National Centre for

Hereditary

Coagulation

Disorders, St

James's Hospital,

Dublin 8

Owen Smith

consultant

haematologist

Correspondence to:

P N Kirke

pkirke@hrb.ie drafted the report VBO'L, AMM, LCB, and OS did the genotyping. PNK and SM recruited some of the cases and PDM provided the Guthrie cards for the controls. LD did the statistical analysis. All authors contributed to writing revisions of the report and approved the final manuscript. PNK is guarantor. Funding: National Institute of Child Health and Human Development, National Institutes of Health (Contract No. NOIHD 23163) and the Health Research Board of Ireland.

Competing interests: None declared.

Ethical approval: Research Ethics Committee of the Health Research Board. We got written informed consent from all participants.

1 Botto LD, Yang Q. 5,10-methylenetetrahydrofolate reductase gene variants and congenital anomalies: a HuGE review. Am I Epidemiol 2000;151:862-77.
2 Mills JL, McPartlin JM, Kirke PN, Lee YJ, Conley MR, Weir DG, et at. Homocysteine metabolism in pregnancies complicated by neural-tube defects. Lancet 1995;345:149-5

3 Shields DC, Kirke PN, Mills JL, Ramsbottom D, Molloy AM, Burke H, et al. The "thermolabile" variant of methylenetetrahydrofolate reductase and neural tube defects: an evaluation of genetic risk and the relative importance of the genotypes of the embryo and the mother. Am J Hum Genet 1999:64:1045-55.

4 Johanning GL, Tamura T, Johnston KE, Wenstrom, KD. Comorbidity of 5,10-methylenetetrahydrofolate reductase and methionine synthase gene polymorphisms and risk for neural tube defects. J Med Genet 2000;37:949-51.

5 Wald DS, Law M, Morris JK. Homocysteine and cardiovascular disease: evidence on causality from a meta-analysis. BMJ 2002;325:1202-8.

(Accepted 3 February 2004)

doi $10.1136 /$ bmj.38036.646030.EE

\title{
Delays in publication of cost utility analyses conducted alongside clinical trials: registry analysis
}

Dan Greenberg, Allison B Rosen, Natalia V Olchanski, Patricia W Stone, John Nadai, Peter J Neumann

Harvard Center for Risk Analysis, Department of Health Policy and Management, Harvard School of Public Health, 718 Huntington Avenue, Boston, MA 02115, USA Dan Greenberg visiting scientist

Natalia V Olchansk research assistant

Peter J Neumann associate professor of policy and decision sciences

Division of Genera Medicine and Primary Care, Beth Israel Deaconess

Medical Center, 330 Brookline

Avenue, Rose 130,

Boston

Allison B Rosen AHRO health services research fellow

Columbia University, 617 West 168th Street, New York,

NY 10032, USA

Patricia W Stone assistant professor of nursing

continued ove

BMJ 2004;328:1536-7
Economic evaluations conducted alongside randomised controlled trials enable analysis of detailed, patient level data on efficacy, cost, and quality of life in a controlled setting. They can provide timely and reliable assessments of value for money, to inform decisions on coverage and reimbursement. ${ }^{1-3}$

The $B M J$ recently decided to consider trial based economic evaluations for publication only if the clinical results are submitted to the journal as well. ${ }^{4}$ We assessed the extent to which cost utility analyses are conducted alongside trials, estimated the time lag between the publication of trials' clinical and economic results, and compared the characteristics of journals publishing the clinical trial data and the cost utility analyses.

\section{Methods and results}

We conducted a systematic search for original English language cost utility analyses published in 1976-2001 by using Medline and other electronic databases. Two readers independently reviewed each study and came to a consensus on whether the analysis was conducted alongside a trial (data on both efficacy and resource use from the trial were used for the analysis). We identified the journal and publication date for each cost utility analysis and the corresponding trial. To assess the study's potential readership and dissemination we used paired sample $t$ tests to compare the mean impact factors of journals in which studies were published and the extent to which publications were subsequently cited by other authors.

Of 533 cost utility analyses identified, $45(8 \%)$ were trial based economic evaluations and covered a variety of clinical areas, particularly cardiovascular disease, cancer, and psychiatry (a full list of studies is available at www.hsph.harvard.edu/cearegistry). We could not determine the lag in publication between the trial and the economic evaluation for four studies, for which a specific trial could not be identified or trial results were

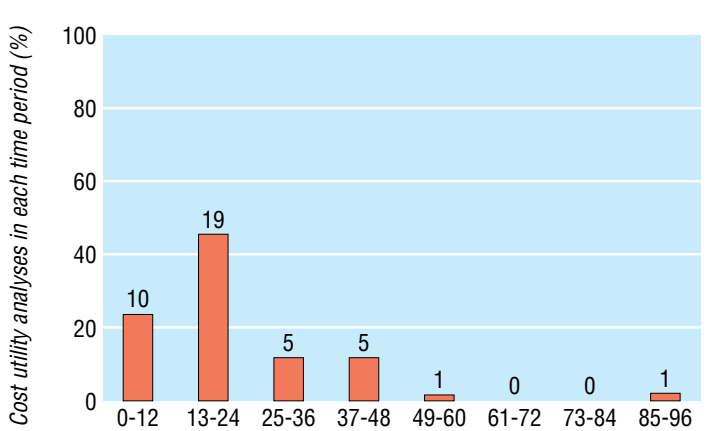

Time (months)

Time from publication of trial's clinical results to publication of economic results $(n=41)$, showing number in each time period. More than $75 \%$ of cost utility analyses were published one year or more after publication of the trial's clinical results

published only in abstract form. In cases where the clinical trial results and economic evaluation were reported in the same article or in the same issue of the journal $(n=7)$, we assumed no lag.

On average, cost utility analyses were published almost two years after the publication of the corresponding trial (mean (SD) 1.8 (1.4) years; range $0-7.5$ years) (figure). Journal impact factors were higher for trials than for cost utility analyses (11.0 $v 4.9$; $t=-3.951(\mathrm{df}=28) ; 95 \%$ confidence interval for the difference -9.25 to $-2.93 ; \mathrm{P}<0.001)$. The mean number of citations per year (total number of citations divided by number of years since the study was published) was also higher for clinical trials than for the economic evaluations (27.4 $v 3.4 ; t=-3.197$ $(\mathrm{df}=30) ; 95 \%$ confidence interval for the difference -39.24 to $-8.64 ; \mathrm{P}=0.003)$.

This article was posted on bmj.com on 20 April 2004: http:// bmj.com/cgi/doi/10.1136/bmj.38079.502326.AE 


\section{Comment}

We found a substantial delay in the publication of cost utility analyses, suggesting that reliable economic data are usually not available, at least in peer reviewed journals, for decision makers when decisions on adoption and reimbursement are typically made. Moreover, compared with trial results, dissemination of cost utility analyses takes place in journals with lower readership and influence. Several factors may contribute to this phenomenon: economic evaluations may be time consuming to construct, as they typically involve projections of trial data over time and across populations through use of modelling techniques and data from external sources; trial sponsors and investigators are eager to report important clinical results first, and more resources are initially allocated to interpreting and publishing these results; given that most readers of clinical journals are physicians, and not economists or policy makers, manuscripts presenting important clinical results are more often assigned by editors to an accelerated review and publication process.

Efforts have recently been made to keep the clinical and economic results of a trial together. ${ }^{4}$ Further efforts (for example, fast track review process) should be made to promote timely dissemination of results of economic evaluations concurrent with or soon after the completion and publication of the trial.

We thank Richard H Chapman for his contribution to the design and analysis of the Harvard School of Public Health Cost-Effectiveness Analysis Registry.

Contributors: DG had the original idea for the study, drafted the first version of the manuscript, did the statistical analysis, and is

\section{What is already known on this topic}

To identify cost effective interventions, decision makers need timely and reliable information about the clinical and economic consequences of treatments

Economic evaluations conducted alongside clinical trials enable analysis of detailed, patient level data on efficacy, cost, and quality of life in a controlled setting

\section{What this study adds}

A substantial delay in the publication of economic evaluations suggests that reliable economic data are usually not available when decisions have to be made

the guarantor. All authors extracted data, interpreted the findings, critically revised the report, and approved the final version.

Funding: Supported by grant number R01 HS10919 from the Agency for Health Care Research and Quality.

Competing interests: None declared.

Gold M, Siegel J, Russel L, Weinstein M, eds. Cost-effectiveness in health and medicine. New York: Oxford University Press, 1996.

2 Drummond M. Introducing economic and quality of life measurements into clinical studies. Ann Med 2001;33:344-9.

3 Drummond MF, O'Brien B, Stoddart GL, Torrance GW. Methods for the economic evaluation of health care programmes. 2nd ed. New York: Oxford University Press, 1997.

4 Smith R. New BMJ policy on economic evaluations. BMJ 2002;325:1124. (Accepted 30 January 2004)

doi 10.1136/bmj.38079.502326.AE

Massachusetts General Hospital, 55 Fruit Street, Weight Center S50-4th floor, Boston

instructor in medicine

Correspondence to: D Greenberg,

Harvard Clinical

Research Institute Rese
930

Commonwealth Avenue, Boston, MA 02215, USA dan.oreenberg@ hcri.harvard.edu

\title{
DRUG POINTS
}

\section{Guillain-Barré syndrome seen in users of isotretinoin}

\author{
J Pritchard, R Appleton, R Howard, R A C Hughes
}

We report Guillain-Barré syndrome in people taking oral isotretinoin, a retinoid drug used in secondary care for severe acne. ${ }^{1}$ The Committee on Safety of Medicines has received one other report of Guillain-Barré syndrome after oral isotretinoin (Committee on Safety of Medicines, private communication).

Case 1-A 31 year old man took $80 \mathrm{mg}$ of oral isotretinoin a day for five weeks, during which he had epistaxis, dry lips, cough, and arthralgia before developing paraesthesiae in his feet and influenza-like symptoms. The next day he could not stand due to an areflexic tetraparesis and needed ventilatory support. Within four days he could only blink.

Case 2-A 13 year old boy took $50 \mathrm{mg}$ of oral isotretinoin a day for two months, stopped for one week, and then took $30 \mathrm{mg}$ a day for six weeks but had epistaxis, lethargy, and headaches. After stopping isotretinoin again for 10 days he developed a flaccid areflexic tetraparesis needing ventilatory support.

Both patients displayed cerebrospinal fluid albuminocytological dissociation. Nerve conduction studies in case 1 showed a motor axonal neuropathy with unrecordable sensory potentials and $\mathrm{F}$ waves, those in case 2, done after 21 months, showed borderline increased $\mathrm{F}$ wave latencies. Both patients received intravenous immunoglobulin IVIg $2 \mathrm{~g} / \mathrm{kg}$ and left hospital within three months. Neither patient has been rechallenged with oral isotretinoin, although the first continued to use topical isotretinoin gel $0.05 \%$ which is not absorbed.

Retinoids affect the development, differentiation, and function of the central nervous system. Sensory neuropathy has been described in patients taking the retinoid drug acitretin. ${ }^{2}$ Over a 19 year period, an estimated 375000 patients have been treated with oral isotretinoin in the United Kingdom (Roche, personal communication), and the annual incidence of Guillain-Barré syndrome is about 2 in 100 000. This is insufficient to establish a causal association between Guillain-Barré syndrome and isotretinoin. We hope to alert others to report similar cases.

We thank the guarantors of Brain.

Funding:JP was funded by a Medical Research Council training fellowship and Brain neurology entry fellowship.

Competing interests: None declared.

1 Webster GF. Acne vulgaris. BMJ 2002;325:475-9.

2 Tsambaos D, Sakkis T, Chroni E, Koniavitou K, Monastirli A, Pasmatzi E, et al. Peripheral sensory neuropathy associated with short term oral acitretin therapy. Skin Pharmacol Appl Skin Physiol 2003;16:46-9.
Department of Clinical

Neurosciences,

Guy's, King's, and St Thomas's School

of Medicine, Guy's

Hospital, London

SE1 1UL

J Pritchard

neurology research

registrar

R A C Hughes professor of neurology

Royal Liverpool

Children's NHS

Trust, Liverpool

R Appleton

consultant paediatric

neurologist

St Thomas's

Hospital, London

R Howard

consultant neurologist

Correspondence to:

J Pritchard

jane.pritchard@

kcl.ac.uk

BMJ 2004;328:1537 